\title{
Evaluation of Fracture Toughness of Ultraviolet-Irradiated Polycarbonate Using the Essential Work of Fracture Method ${ }^{\dagger}$
}

\author{
Celio Jorge Vasques de Oliveira ${ }^{a}$, Ricardo Ponde Weber ${ }^{a}$, Sergio Neves Monteiro ${ }^{a}$ (),
}

\author{
Hélio Carvalho Vital, Marcos Lopes Dias
}

${ }^{a}$ Seção de Engenharia Mecânica e de Materiais, Instituto Militar de Engenharia, Praça General Tibúrcio, 80, Urca, 22291-270, Rio de Janeiro, RJ, Brasil

${ }^{b}$ Instituto de Defesa Química, Biológica, Radiológica e Nuclear, Av. das Américas, 28.705, Guaratiba, 23020-470, Rio de Janeiro, RJ, Brasil

'Instituto de Macromoléculas, Universidade Federal do Rio de Janeiro, Av. Horácio Macedo, 2.030, Cidade Universitária, 21941-598, Rio de Janeiro, RJ, Brasil

Received: December 10, 2017; Revised: June 04, 2018; Accepted: July 05, 2018

The essential work of fracture (EWF) method provides useful parameters to characterize the fracture toughness of polymers exposed to degrading environments under conditions associated with plane-stress state of failure. Exposure of polymeric engineering materials to ultraviolet (UV) radiation may produce macromolecular changes that impair their fracture toughness. In the present work, for the first time, the EWF method applying a double edge notched tensile specimen was used to quantify the fracture toughness behavior of polycarbonate (PC) exposed to different, $300 \mathrm{~h}$ and $600 \mathrm{~h}$, UV irradiation times. In addition, molar weight $\left(\overline{\mathrm{M}}_{\mathrm{n}}\right)$ determination, differential scanning calorimetry (DSC), Fourier transformed infrared spectroscopy (FTIR) and tensile tests were also investigated for non-irradiated and UV irradiated PC. The EWF results and scanning electron microscopy analysis revealed a significant reduction $(39 \%$ for $300 \mathrm{~h}$ and $45 \%$ for $600 \mathrm{~h}$ of UV exposure) in fracture toughness associated with scission of the macromolecular chains. Other investigated properties, such as $\overline{\mathrm{M}}_{\mathrm{n}}$, glass transition temperature, oxidation index and tensile strength, despite decreasing with UV exposure, did not show conclusive values.

Keywords: Polycarbonate, ultraviolet irradiation, Essential Work of Fracture.

\section{Introduction}

The resistance to crack propagation in a material is defined as fracture toughness, which can be evaluated using fracture mechanic concepts ${ }^{1}$ by different methods, such as Crack Extension, Force G, Crack Opening displacement, J Integral, R Curve and Essential Work of Fracture. The Essential Work of Fracture (EWF) method was proposed in 1977 by Cotterell and Reddel ${ }^{2}$ following fundamental ideas of Broberg ${ }^{3-5}$ and originally developed for thin sheets of ductile metals ${ }^{2}$. It was later used to evaluate the fracture toughness of polymer and composite materials ${ }^{6-9}$. Based on principles of fracture mechanics, the method predicts that a region with non-elastic behavior at the crack tip can be subdivided into two distinct regions (Figure 1): a region where the fracture process occurs and a ductile region subjected to the plastic deformation necessary to accommodate tensions ${ }^{2,10,11}$.

Characterization of ductile fractures is based on the distribution of the fracture work, $\mathrm{W}_{f}$, in two parts: (i) the work spent in the zone of the fracture process, $\mathrm{W}_{e}$, which is considered to be essential for the occurrence of the fracture and is independent of the geometry, and (ii) the work responsible

"e-mail: snevesmonteiro@gmail.com

Article presented in the ABM Week 2017, October 2nd to 6th, 2017, São Paulo, SP, Brazil

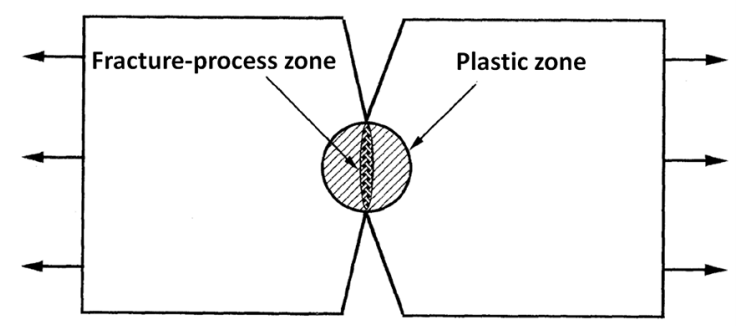

Figure 1. Schematic showing the zone of fracture process and a plastic zone around the ligament in a double edge notched tensile (DEN-T) specimen. Adapted with permission from Hashemi ${ }^{13}$.

for the plastic deformation that depends on the geometry, $\mathrm{W}_{\mathrm{p}}$, but is not considered essential for the fracture process ${ }^{2}$.

The total energy absorbed during the fracture process, $\mathrm{W}_{f}$, can be calculated:

$$
W_{f}=W_{e} L B+W_{p} \beta L^{2} B
$$

where $\mathrm{L}$ is the ligament length of the sample, $\mathrm{B}$ is the sample thickness and $\beta$ is the shape factor of the area subjected to plastic deformation. 
It is important to note that the first term is proportional to the fracture area, while the second term is proportional to the volume of the region around the fractured area. In the case of polymers, normalizing Eq. (1) with respect to the fracture area, it is obtained ${ }^{12}$

$$
W_{F}=\frac{W_{f}}{L B}=W_{e}+W_{p} \beta L
$$

The principle of this technique is fundamentally based on the measurement of the stress versus displacement curve in a tensile test. Figure 2 a shows a schematic plot of the characteristic curves obtained from EWF tests. The area under these curves represents the energy involved in the fracture process, corresponding to the magnitude of $\mathrm{W}_{\mathrm{f}}^{6}$.

The essential work of fracture, $\mathrm{W}_{\mathrm{e}}$, can be determined ${ }^{2}$ by plotting $\mathrm{W}_{\mathrm{f}}$ as a function of the ligament length, $\mathrm{L}$, as schematically illustrated in Fig.2(b)

Among ductile polymers, polycarbonate (PC) tends to show brittle transition in association with specimens presenting small thickness ${ }^{13,14}$, under notched conditions ${ }^{15,16}$, high strain rate $^{17}$ and subjected to gamma radiation ${ }^{18,19}$. In fact, a ductilebrittle transition in PC is well recognized ${ }^{14,20}$. Moreover, its fracture toughness could be determined by the EWF method for possible engineering applications, such as the exposure to gamma radiation in nuclear track detection and medical instruments sterilization ${ }^{19}$. Ultraviolet irradiation (UV) is also used for sterilization process because, unlike the ethylene oxide process (ETO), it leaves no residual toxic products. However, ionizing irradiation may change the mechanical properties of polymers by producing scission or crosslinking, depending on the radiation dose ${ }^{21}$. In PC subjected to thermal degradation ${ }^{22}$, gamma ${ }^{23}$ of UV irradiation ${ }^{24}$, scission may occur in the carbonyl group or, with less probability, in the benzene rings. In particular, the characterization of the amount of damage caused by UV irradiation to PC has not yet been performed. Therefore, in the present work the fracture toughness of PC exposed to different doses of UV irradiation was evaluated by the EWF method. The main motivation of this investigation is to be able, for the first time, to quantify changes in fracture toughness of PC due to UV irradiation using parameters determined by EWF results. The advantage of applying EWF over other conventional fracture toughness measurements, like common uniaxial tests, is due to the higher sensibility of EWF to different radiation dose as further discussed.

\section{Experimental}

\subsection{Materials and methods}

A commercial grade polycarbonate (PCLIGHT ${ }^{\mathrm{TM}}$ ) supplied by Policarbonatos do Brasil was used. Double-edge-notched tensile, DEN-T, specimens $1 \mathrm{~mm}$ thick, schematically shown in Fig. 1, were prepared by machining steps performed on a rectangular sheet $(2050 \mathrm{~mm}$ ( $3050 \mathrm{~mm}$ ). The PC DEN-T samples were separated in three batches: non-irradiated, exposed to a 300 hours and exposed to a 600 hours of UV irradiation. The samples were evaluated by physicochemical methods to correlate the fracture toughness with changes in the macromolecular structure of the PC introduced by UV irradiation.
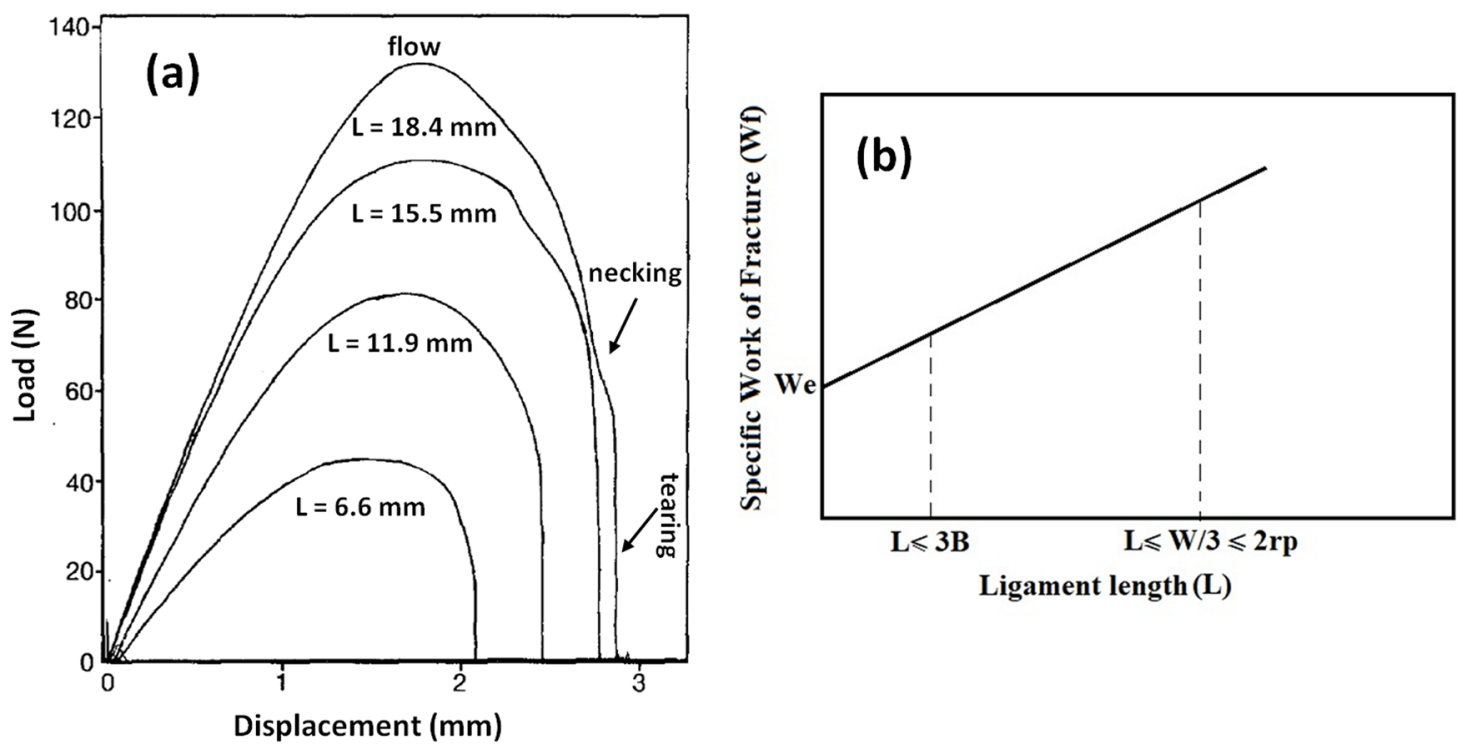

Figure 2. Schematic examples of: (a) characteristic curves from the EWF test of PC film samples with different ligament lengths and (b) plot of $\mathrm{W}_{\mathrm{e}}$ vs. L. Adapted with permission from Hashemi ${ }^{13}$. 


\subsection{UV Irradiation}

The exposure of the samples to UV radiation was performed using an accelerated aging system for non-metallic materials with ultraviolet "B" rays (UVB), following the standard guidelines of ASTM G-15425. The exposure times chosen were 300 and 600 hours with the samples remained in direct contact with air. The samples were located at $5 \mathrm{~cm}$ of distance away from the UV sources emitting a spectrum peaking at the wavelength of $306 \mathrm{~nm}$, as proposed elsewhere ${ }^{26}$.

\subsection{Determination of number average molar weight}

The number average molar weight determination was performed at room temperature by gel permeation chromatography on a model RID 20A Shimadzu chromatographic system for both non-irradiated and UV irradiated samples. The equipment software was used to calculate the number average molecular weight $\left(\overline{\mathrm{M}}_{\mathrm{n}}\right)$ and the polydispersion.

\subsection{Thermal analysis}

Differential Scanning Calorimetry (DSC) tests were performed on a PerkinElmer STA 6000 Thermal Analyzer to measure the glass transition temperatures $\left(\mathrm{T}_{\mathrm{g}}\right)$ associated with the second order transitions, according to ASTM D3418-1527. Experiments were conducted by subjecting non-irradiated and irradiated samples, with masses of approximately $20 \mathrm{mg}$, to a double heating cycle of $30^{\circ} \mathrm{C}$ to $800^{\circ} \mathrm{C}$ at a heating rate of $10^{\circ} \mathrm{C} / \mathrm{min}$ under nitrogen atmosphere with a flow rate of $20 \mathrm{~mL} / \mathrm{min}$. Only the results obtained in the second heating cycle were considered, since the first is used to erase the thermal history of the material ${ }^{22}$.

\subsection{Infrared spectroscopy (FTIR)}

Infrared spectroscopy was performed on an IS50 Smart ITR Spectrometer in the wave number range $400-4000 \mathrm{~cm}^{-1}$. This test was aimed at evaluating structural changes in the macromolecules of the UV irradiated material in order to correlate the radiation dose with the presence of oxygenated functional groups such as carbonyl.

For the determination of the degradation caused by the exposure of the material to UV irradiation, the oxidation index (OI) was calculated as the ratio between the intensity of the peak at $1762 \mathrm{~cm}^{-1}$, due to stretching of the carbonyl functional group, and the intensity of the peak at $827 \mathrm{~cm}^{-1}$, associated with flexing of the aromatic ring out of the plane ${ }^{24}$.

$$
O I=\frac{I(1762)}{I(827)}
$$

\subsection{Tensile tests}

The tensile properties, before and after UV irradiation, were determined using an INSTRON 5900 universal test machine at room temperature (RT), with a crosshead speed of $5 \mathrm{~mm} / \mathrm{min}$, according to ASTM D638-1428.

\subsection{Essential work of fracture tests}

The fracture toughness analysis by the EWF method for both UV irradiated and non-irradiated PC was performed using the protocol established elsewhere ${ }^{6,29}$. For each set of ligaments, the following lengths were used: $4.0 \mathrm{~mm}, 6.0$ $\mathrm{mm}, 8.0 \mathrm{~mm}, 10.0 \mathrm{~mm}$ and $12.0 \mathrm{~mm}$. Twenty five DEN-T specimens $120 \mathrm{~mm}$ long, $30 \mathrm{~mm}$ wide and $1.0 \mathrm{~mm}$ in thick (Fig. 1) were subjected to a RT tensile tests, with a crosshead speed of $1 \mathrm{~mm} / \mathrm{min}$.

\subsection{Fractography analysis}

The fractographic analysis was performed to determine the fracture mechanisms produced by EWF test and to identify the fracture mode (ductile or brittle) ${ }^{26}$. This allows the correlation of the fracture mode with mechanical tests results before and after UV irradiation. The fracture surfaces were analyzed by scanning electron microscopy (SEM) on a Tescan Mira 3 system. Before this procedure, the fractured surfaces were coated with gold under vacuum.

\section{Results and Discussion}

\subsection{Number average molar weight determination}

Chromatograms of non-irradiated and irradiated samples (300h and 600h UV), are shown in Figure 3.

The number average molar weight $\left(\overline{\mathrm{M}}_{\mathrm{n}}\right)$ and polydispersion $\left(\frac{\overline{M W}}{\overline{M n}}\right)$, calculated from the chromatograms in Fig. 3, are shown in Table 1.

In this table, a slight decrease of the number average molar weight with irradiation can be verified. Additionally, it is observed that the polydispersity is higher in the irradiated samples. In Table 1, as well in subsequent tables, the values of non-irradiated PC display in parenthesis $100 \%$ or 1 for comparison with changes produced in the other values of UV irradiated conditions. This behavior, characterized by a decrease in molar weight and an increase in polydispersity, can be related to a backbone scission of the polymeric chains $^{23,30}$. In terms of amount of scissions, the results in Table 1 indicate a damage of $1 \%$ after $300 \mathrm{~h}$ and $4 \%$ after $600 \mathrm{~h}$ of irradiation.

\subsection{Thermal analysis}

Figure 4 depicts the characteristic DSC curves obtained before and after UV irradiation. In Table 2, the glass transition temperatures $\left(\mathrm{T}_{\mathrm{g}}\right)$ obtained from the DSC curves in Fig. 4 are presented.

One can see a decrease in the glass transition temperature with increasing time of UV irradiation exposure. These results confirm the probable backbone chain scission because smaller molecular weights are associated with increasing 

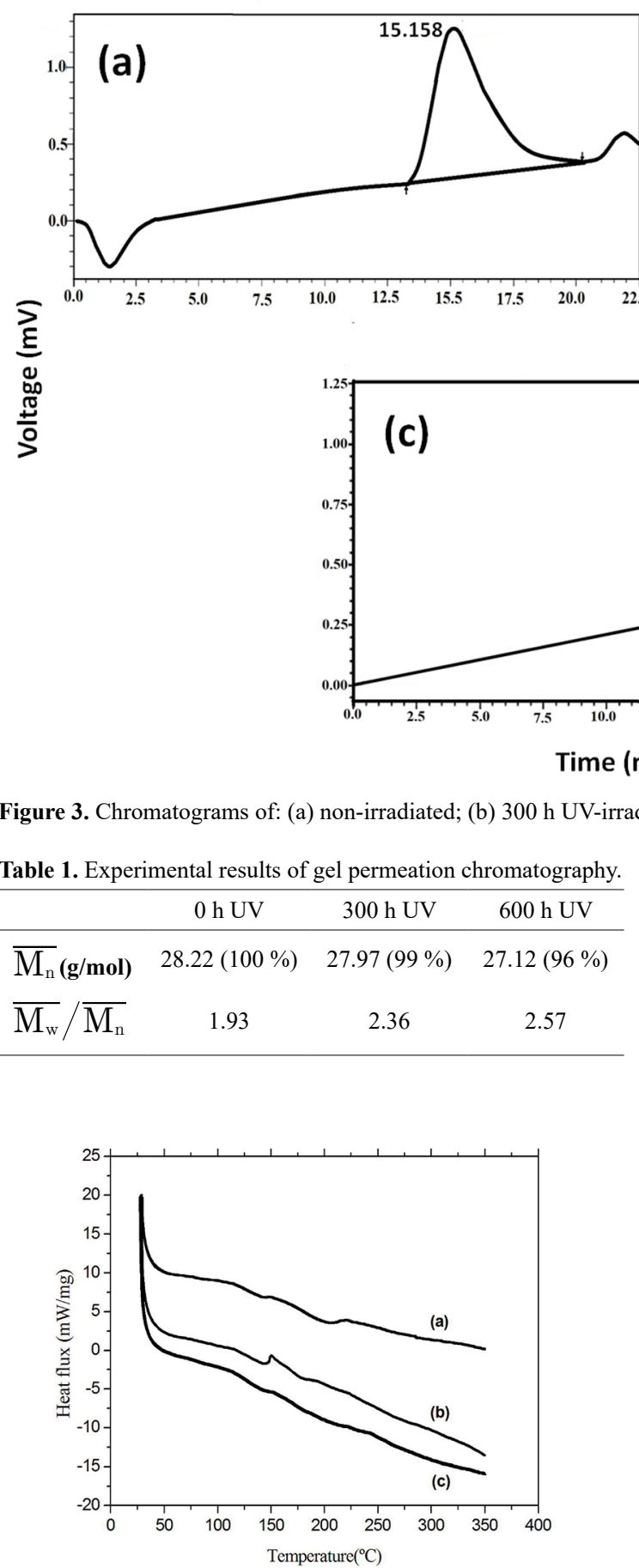

Figure 4. DSC curves for non-irradiated (a) as well as 300 hours (b) and 600 hours (c) UV-irradiated PC.

macromolecule mobility ${ }^{22}$. A possible quantification of this effect, Table 2, suggests a linear loss of $1 \%$ in $\mathrm{T}_{\mathrm{g}}$ after 300 $\mathrm{h}$ and $2 \%$ after $600 \mathrm{~h}$ of irradiation.

\subsection{FTIR}

Figure 5 shows the FTIR spectra before and after UV irradiation displaying the intensities of absorbance peaks
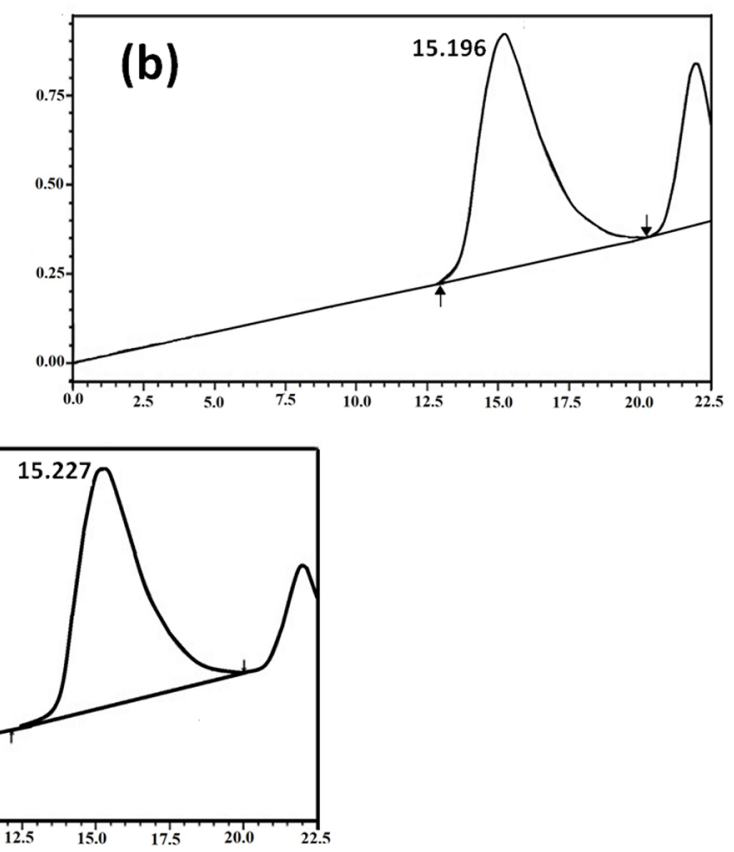

\section{in)}

; and (c) 600 h UV-irradiated specimens.

Table 2. Glass transition temperature of the samples.

\begin{tabular}{lc}
\hline Condition & $\begin{array}{c}\text { Glass Transition } \\
\left({ }^{\circ} \mathrm{C}\right)\end{array}$ \\
\hline $\mathbf{0}$ h UV & $149.6(100 \%)$ \\
$\mathbf{3 0 0}$ h UV & $147.4(99 \%)$ \\
$\mathbf{6 0 0}$ h UV & $146.4(98 \%)$ \\
\hline
\end{tabular}

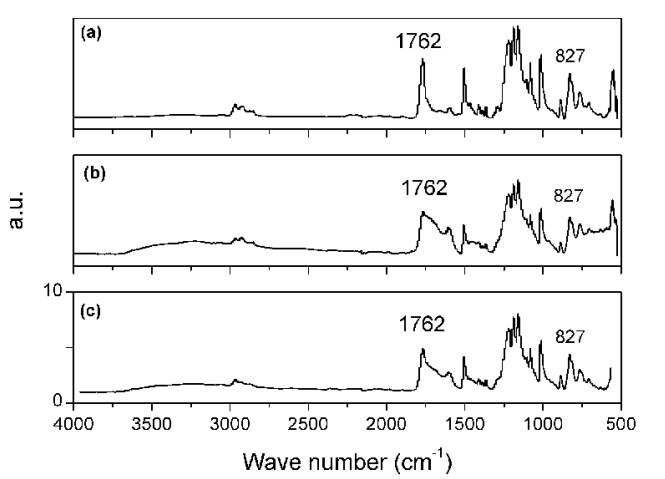

Figure 5. FTIR spectra of non-irradiated (a) as well as 300 hours (b) and 600 hours (c) UV-irradiated PC.

associated with the functional groups expressed as a function of the material's characteristic wave number. The carbonyl peak was used to determine the oxidation index (OI) with regard to the UV irradiation dose. Table 3 presents these indexes before and after UV irradiation.

In this table, practically the same reduction of $12-13 \%$ in OI is observed for both UV irradiation times. This decrease 
Table 3. Oxidation index (OI) of samples.

\begin{tabular}{lccc}
\hline & 0 h UV & $300 \mathrm{~h} \mathrm{UV}$ & $600 \mathrm{~h} \mathrm{UV}$ \\
\hline I(1762) & 5.32 & 3.89 & 3.87 \\
I (827) & 4.08 & 3.44 & 3.39 \\
OI & $1.30(100 \%)$ & $1.13(87 \%)$ & $1.14(88 \%)$ \\
\hline
\end{tabular}

of the oxidation index suggests that the macromolecular chains were broken at the carbonyl group ${ }^{23,24,30}$ due to UV irradiation but independent of the dose.

\subsection{Tensile tests}

The tensile stress-strain curves of PC, before and after UV irradiation are shown in Fig. 6. The tensile properties values of ultimate stress and elongation at break, determined from the stress-strain curves of UV irradiated and non irradiated PC, are presented in Table 4.

Practically the same pronounced decreasing in the elongation at break of $64-65 \%$ is verified for both irradiation times. By contrast, a smaller reduction in the tensile strength of $9-10 \%$ is noticed for both UV time exposures. The elongation reduction is attributed to a smaller molecular weight, as found in gamma irradiated samples ${ }^{19,31,8,32}$, which reduces the plastic deformation capacity of the material. In the case of tensile strength, the relatively small reduction might be assigned to the decrease in PC molecular length due to chain scission ${ }^{12}$. In both cases, elongation and strength, the change in irradiation time does not seem to affect these tensile properties.

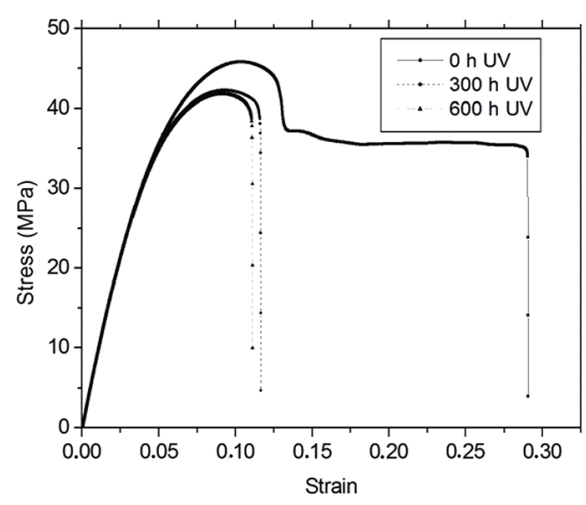

Figure 6. Stress-strain curves of PC, before and after UV irradiation.

Table 4. Ultimate stress and elongation at break of the samples.

\begin{tabular}{lcc}
\hline Condition & $\begin{array}{c}\text { Elongation at break } \\
(\%)\end{array}$ & Ultimate stress (MPa) \\
\hline $\mathbf{0}$ h UV & $33.71(100 \%)$ & $46.23(100 \%)$ \\
$\mathbf{3 0 0}$ h UV & $11.89(35 \%)$ & $42.27(91 \%)$ \\
$\mathbf{6 0 0}$ h UV & $11.46(34 \%)$ & $41.79(90 \%)$ \\
\hline
\end{tabular}

\subsection{EWF tests}

Figure 7 shows the load-displacement (F vs 1) curves for different ligament lengths $(4 \mathrm{~mm}, 6 \mathrm{~mm}, 8 \mathrm{~mm}, 10 \mathrm{~mm}$ and $12 \mathrm{~mm}$ ) of non-irradiated and irradiated samples as a function of exposure times of 300 hours and 600 hours to UV irradiation.

Figure 8 presents the specific work of fracture $\mathrm{W}_{\mathrm{f}}$ (calculated by area under the load-displacement curve) as a function of the ligament length $\mathrm{L}^{28}$. For all samples, the data were adjusted to straight lines by least square fit.

The value of $\mathrm{W}_{\mathrm{e}}$ is determined extending the regression lines to $\mathrm{L}=0$. The results of this extensions are shown in Table 5 .

This table shows a significant decrease in the value of $\mathrm{W}_{\mathrm{e}}$ after exposure to UV radiation. Indeed, 300 hours and 600 hours of exposure caused $\mathrm{W}_{\mathrm{e}}$ reductions of $39 \%$ and $45 \%$, respectively. These reductions are probably due to scission of the polymer chains and an associated decrease in the plastic deformation capacity ${ }^{19}$. As compared with the tensile test results, Fig. 6 and Table 4, the EWF results in Fig. 8 and Table 5 reveal not only a significant decrease in $\mathrm{W}_{\mathrm{e}}$ but also, even more important, that this essential work of fracture decreases sensibly with the irradiation time. This decrease has a tendency to asymptotically level around 1,000 hours of UV irradiation, corresponding to a value of about $45 \%$. As aforementioned, $\mathrm{W}_{\mathrm{e}}$ is the essential work for the occurrence of fracture, independent of the specimen geometry, and directly related to the material fracture toughness resistance. Therefore, for the first time, the fracture toughness of a relatively plastic material, PC in the present work, is quantitatively shown to decrease with UV radiation dose.

On the other hand, the results obtained for the non-essential work of fracture $(\mathrm{Wp} \beta)$, which represents the plastic energy stored around the ligament of the specimen and depends on its geometry, suffer relatively small, $12-14 \%$, increase for the different UV doses. This indicates that there was only a minor loss in the plastic energy absorption capacity during the mechanical solicitation, probably favored by plane-stress condition in the ligament $t^{8,32-34}$.

\subsection{Fractography analysis}

The fracture analysis for the non-irradiated samples subjected to the EWF fracture toughness test was performed through micrographs, such as the one presented in Fig. 9. In this figure, a typical fracture surface is observed, similar to all other micrographs, where nucleation and propagation of cracks occurred at the notches. This is a region energetically favorable to crack initiation, due to the concentration of the local stress. In fact, cracks propagate in the central region of the fractured surface where "necking" process is taking place. This is followed by plastic tearing, as highlighted 

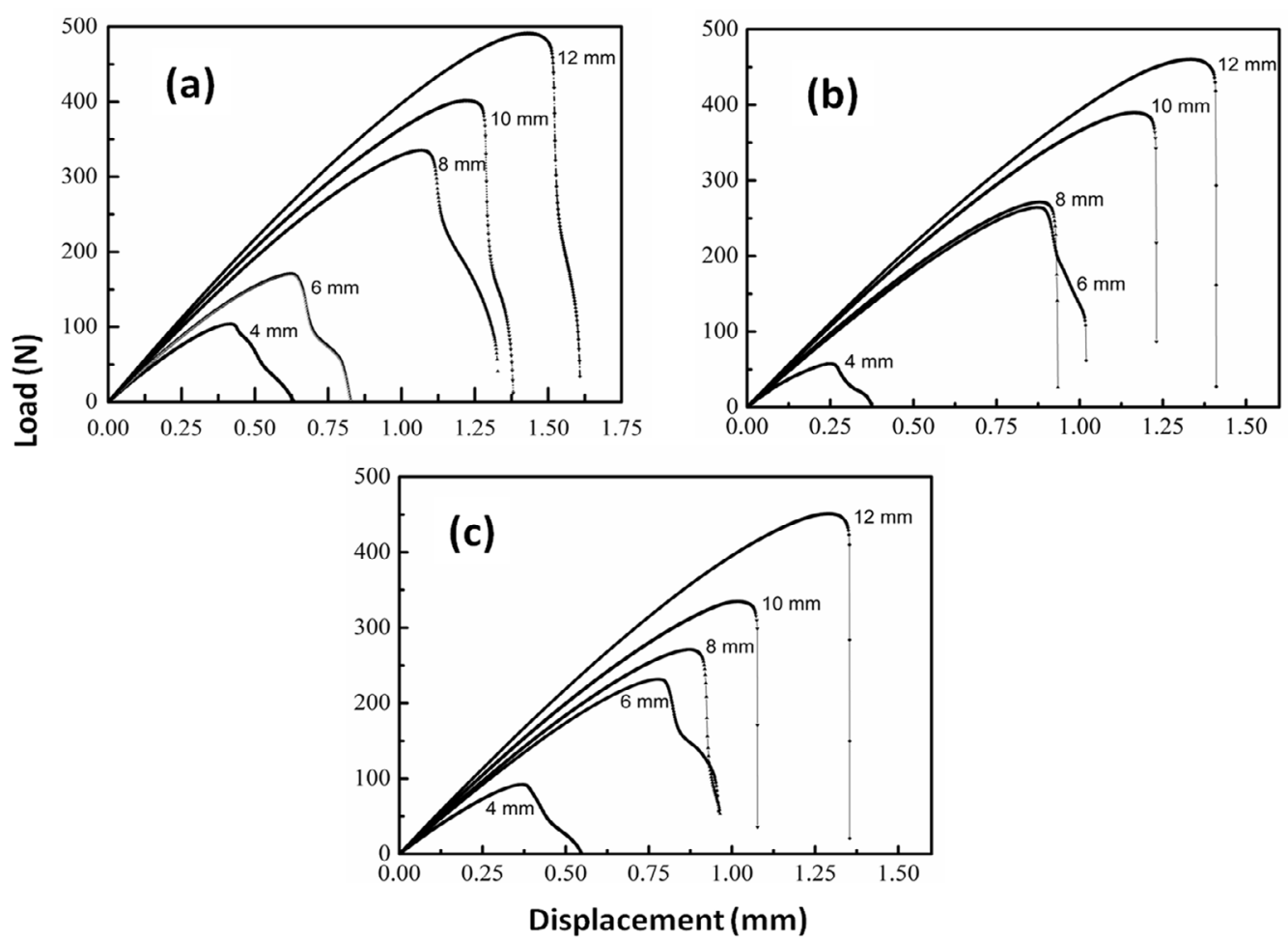

Figure 7. Force vs ligament length curves of DEN-T specimens with different ligament lengths $(4,6,8,10$ and $12 \mathrm{~mm})$ for (a) non-irradiated; (b) 300h UV and (c) 600h UV irradiated PC.

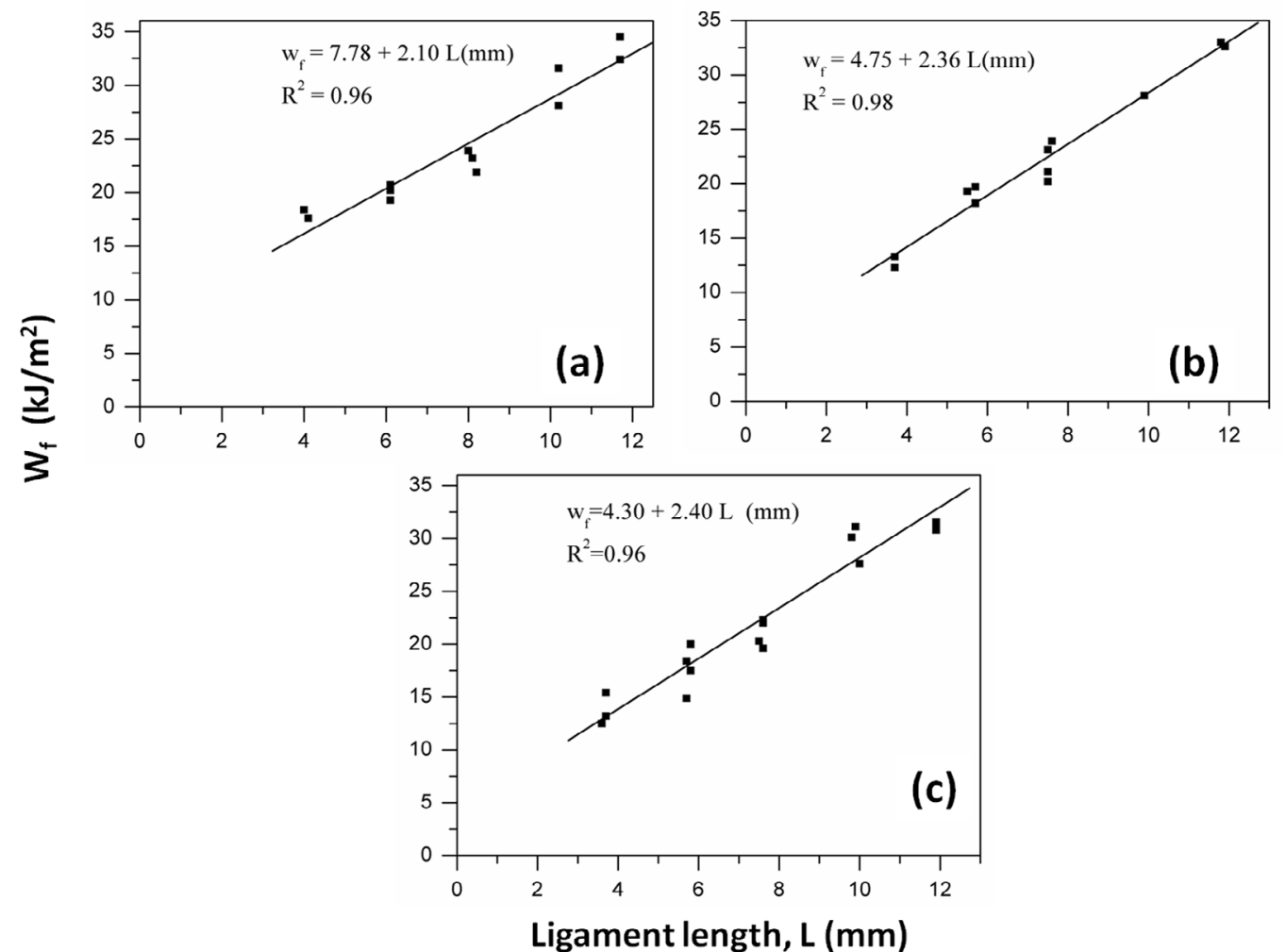

Figure 8. Specific work of fracture $\left(\mathrm{W}_{\mathrm{f}}\right)$ versus ligament length (L) for (a) non-irradiated; (b) $300 \mathrm{~h} \mathrm{UV}$ and (c) $600 \mathrm{~h} \mathrm{UV}$ irradiated specimens. 
Table 5. Essential work of fracture (We) and non-essential work of fracture $(\mathrm{Wp} \beta)$ of samples.

\begin{tabular}{lcc}
\hline Condition & $\mathrm{W}_{\mathrm{e}}\left(\mathrm{kJ} / \mathrm{m}^{2}\right)$ & $\mathrm{W}_{\mathrm{p}} \beta\left(\mathrm{MJ} / \mathrm{m}^{3}\right)$ \\
\hline 0 h UV & $7.78 \pm 1.55(100 \%)$ & $2.10 \pm 0.19(1)$ \\
300 h UV & $4.75 \pm 1.05(61 \%)$ & $2.36 \pm 0.14(1.12)$ \\
600 h UV & $4.30 \pm 1.48(55 \%)$ & $2.40 \pm 0.19(1.14)$ \\
\hline
\end{tabular}

in Fig. 9, which is consistent with the results obtained in mechanical tests of $\mathrm{EWF}^{19,26}$.

Figure 10 shows the fracture morphology observed for samples subjected to the EWF test and exposed to UV radiation for 300 hours and 600 hours. In this figure, multifaceted flat surfaces are seen in hyperbolic forms, mostly brittle, which come from the encounter of main cracks originated

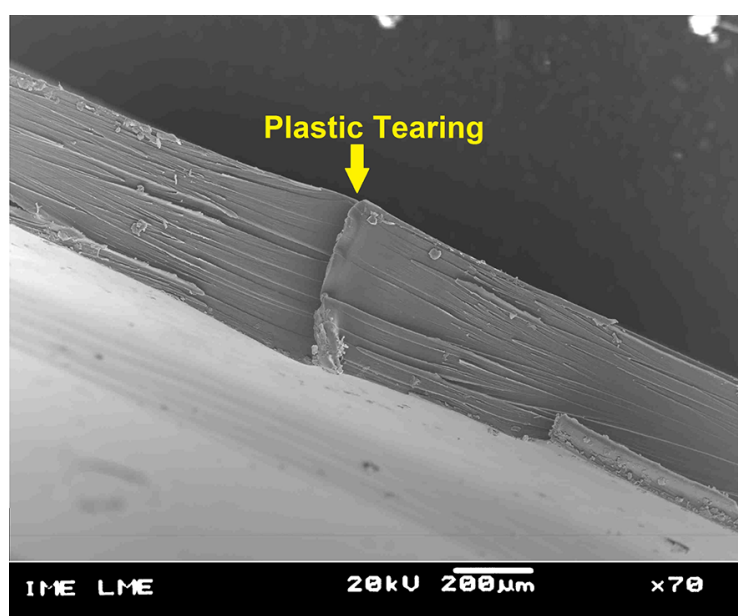

Figure 9. Central region of fracture surface of a non-irradiated specimen subjected to the EWF test for a $12 \mathrm{~mm}$ ligament length.

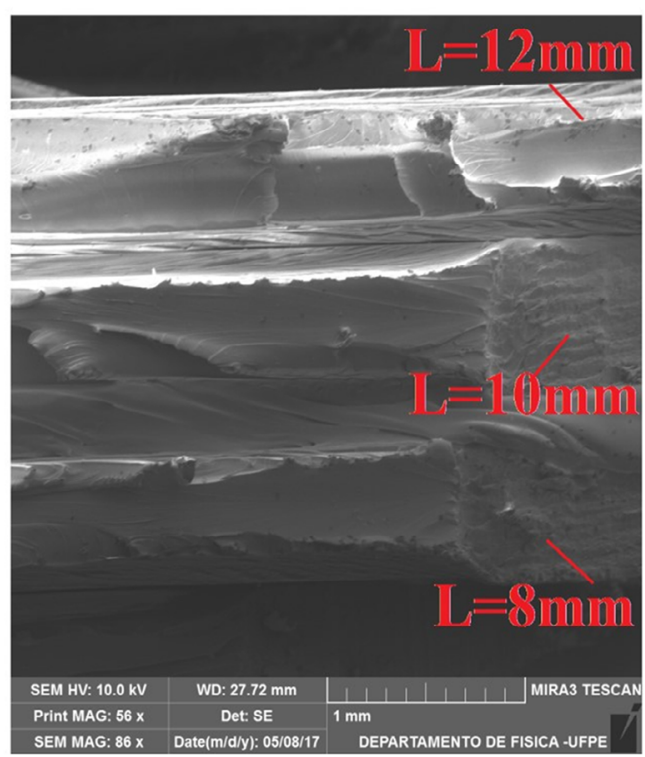

(a) in the regions subsequent to the notches, with secondary cracks in nucleation points on the surface. These points are probably associated with the more pronounced molecular chain scission on the surface of the material, reducing their plastic deformation capability during loading ${ }^{19}$.

\section{Summary and Conclusions}

In this work, the fracture toughness of polycarbonate (PC) was measured by the EWF method in non-irradiated condition and after 300 and $600 \mathrm{~h}$ of UV irradiation. Determination of molar weight $\left(\overline{\mathrm{M}}_{\mathrm{n}}\right)$, calorimetry (DSC), Fourier transformed infrared spectroscopy (FTIR), and tensile tests were also performed for both non-irradiated and UV-irradiated conditions.

- UV irradiation caused a decrease in $\overline{\mathrm{M}}_{\mathrm{n}}$ of only $1 \%$ after $300 \mathrm{~h}$ and $4 \%$ after $600 \mathrm{~h}$ of exposure. As for the DSC results, UV radiation exposure also caused minor loss, around 1-2 \%, in the glass transition temperature $\left(\mathrm{T}_{\mathrm{g}}\right)$ for both exposure times.

- The oxidation index (OI) measured by carbonyl peaks in the FTIR spectra was reduced by approximately the same amount of $12-13 \%$ for both exposure times. This indicates that PC macromolecular chains were broken at the carbonyl group.

- Tensile tests showed a pronounced decrease, 64-65 $\%$, in plastic elongation together with a moderate decrease, $9-10 \%$, in tensile strength due to both exposure times. This was attributed to PC decrease in molar weight by chain scission.

- $\quad$ All the properties: molar weight, $\mathrm{T}_{\mathrm{g}}, \mathrm{OI}$, and tensile strength display relatively small and practically the

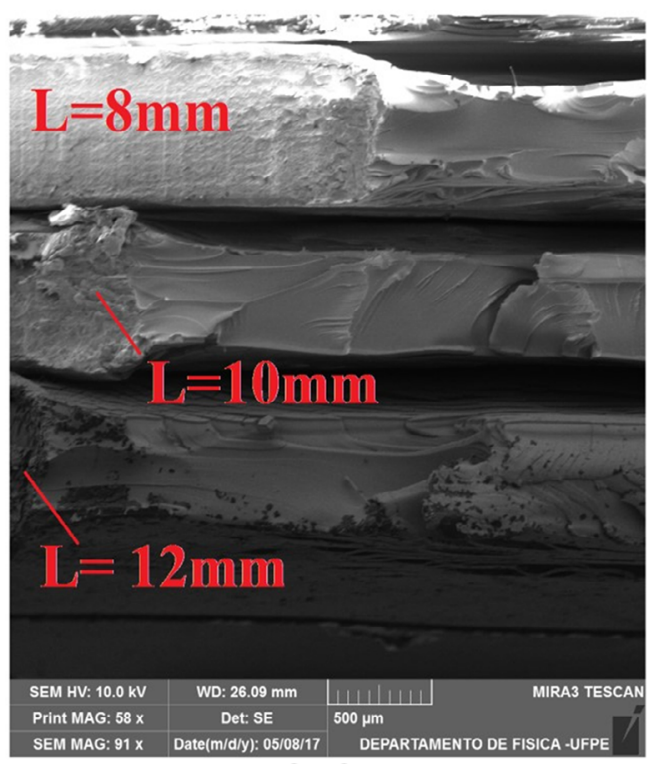

(b)

Figure 10. Fracture surface of specimens subjected to the EWF test and exposed to UV radiation for (a) 300 hours and (b) 600 hours, with their respective ligament lengths 
same effect of UV radiation exposure. They do not seem to be sensible to exposure time.

- On the contrary, the essential work of fracture $\left(\mathrm{W}_{\mathrm{e}}\right)$ revealed a sensible fracture toughness decrease, by EWF tests, of 39 and $45 \%$, respectively, for UV radiation exposure of 300 and $600 \mathrm{~h}$. This was assigned to scission of PC macromolecular chains and corroborated by SEM fracture surface observation.

\section{Acknowledgements}

The authors thank the support by the Brazilian agencies: CNPq, CAPES and FAPERJ.

\section{References}

1. Meyers MA, Chawla KK. Mechanical Behavior of Materials. $2^{\text {nd }}$ ed. Cambridge: Cambridge University Press; 2009.

2. Cotterell B, Reddel JK. The essential work of plane stress ductile fracture. International Journal of Fracture. 1977;13(3):267-277.

3. Broberg KB. Critical review of some theories in fracture mechanics. International Journal of Fracture Mechanics. 1968;4(1):11-19.

4. Broberg KB. Crack-growth criteria and non-linear fracture mechanics. Journal of the Mechanics and Physics of Solids. 1971;19(6):407-418.

5. Broberg KB. On stable crack growth. Journal of the Mechanics and Physics of Solids. 1975;23(3):215-237.

6. Clutton E. Essential Work of Fracture. In: Moore DR, Pavan A, Willians JG, eds. Fracture Mechanics Testing Method for Polymers Adhesives. ESIS Publication 28. Oxford: Elsevier Science; 2001. p. 177-187.

7. Fasce L, Bernal C, Frontini P, Mai YW. On the impact of essential work of fracture of ductile polymers. Polymer Engineering and Science. 2001;41(1):1-14

8. Bárány T, Czigány T, Karger-Kocsis J. Application of the essential work of fracture (EWF) concept for polymers, related blends and composites. A review. Progress in Polymer Science. 2010;35(10):1257-1287.

9. Al-Jabareen A, Illescas S, Maspoch ML, Santana OO. Essential work of fracture testing of PC-rich PET/PC blends with and without transesterification catalysts. Journal of Materials Science. 2010;45(11):2907-2915.

10. Anderson TL. Fracture Mechanics Fundamentals and Applications. $3^{\text {rd }}$ ed. Boca Raton: CRC Press; 2005.

11. Broek D. Elementary Engineering Fracture Mechanics. $3^{\text {rd }}$ ed. The Hague: Martinus Nijhoff Publishers; 1984.

12. Luna P, Bernal C, Cisilino A, Frontini P, Cotterell B, Mai YW. The application of the essential work of fracture methodology to the plane strain fracture of ABS 3-point bend specimens. Polymer. 2003;44(4):1145-1150.
13. Hashemi S. Plane-stress fracture of polycarbonate films. Journal of Materials Science. 1993;28(22):6178-6184.

14. Parvin M, Williams JG. Ductile-brittle fracture transitions in polycarbonate. International Journal of Fracture. 1975;11(6):963972 .

15. Fraser RAW, Ward IM. The impact fracture behaviour of notched specimens of polycarbonate. Journal of Materials Science. 1977;12(3):459-468.

16. Mills NJ. The mechanism of brittle fracture in notched impact tests on polycarbonate. Journal of Materials Science. 1976;11(2):363-375.

17. Gaymans RJ, Hamberg MJJ, Inberg JPF. The brittle-ductile transition temperature of polycarbonate as a function of test speed. Polymer Engineering and Science. 2000;40(1):256-262.

18. de Melo NS, Weber RP, Suarez JCM. Toughness behavior of gamma-irradiated polycarbonate. Polymer Testing. 2007;26(3):315322.

19. Weber RP, Monteiro SN, Suarez JCM, Figueiredo ABHS, Oliveira CJV. Fracture toughness of gamma irradiated polycarbonate sheet using the essential work of fracture. Polymer Testing. 2017;57:115-118.

20. Chang FC, Chu LH. Co-existence of ductile, semi-ductile, and brittle fractures of polycarbonate. Journal of Applied Polymer Science. 1992;44(9):1615-1623.

21. Zakariya NI, Khan MTE. Benefits and Biological Effects of Ionizing Radiation. Scholars Academic Journal of Biosciences. 2014;2(9):583-591.

22. Rivaton A, Mailhot B, Soulestin J, Varghese H, Gardette JL. Comparison of the photochemical and thermal degradation of bisphenol-A polycarbonate and trimethylcyclohexane-polycarbonate. Polymer Degradation and Stability. 2002;75(1):17-33.

23. Gupta DP, Kumar S, Kalsi PC, Manchanda VK, Mittal VK. $\gamma$-Ray Modifications of Optical/Chemical Properties of Polycarbonate Polymer. World Journal of Condensed Matter Physics. 2015;5(3):129-137.

24. Rajan VV, Wäber R, Wieser J. Comparative investigation of the ultraviolet stabilization of polycarbonate/poly(acrylonitrilebutadiene-styrene) with different ultraviolet absorbers. Journal of Applied Polymer Science. 2012;124(5):3988-3995.

25. ASTM International. ASTM G154-16 - Standard Practice for Operating Fluorescent Ultraviolet (UV) Lamp Apparatus for Exposure of Nonmetallic Materials. West Conshocken: ASTM International; 2016.

26. Jaleh B, Shahbazi N. Surface properties of UV irradiated $\mathrm{PC}-\mathrm{TiO}_{2}$ nanocomposite film. Applied Surface Science. 2014;13:251-258.

27. ASTM International. ASTM D3418-15 - Standard Test Method for Transition Temperatures and Enthalpies of Fusion and Crystallization of Polymers by Differential Scanning Calorimetry. West Conshohocken: ASTM International; 2015.

28. ASTM International. ASTM D638 - Standard Test Method for Tensile Properties of Plastics. West Conshohocken: ASTM International; 2014. 
29. Ho CH, Vu-Khanh T. Physical aging and time-temperature behavior concerning fracture performance of polycarbonate. Theoretical and Applied Fracture Mechanics. 2004;41(1-3):103-114.

30. Bahniwal S, Sharma A, Aggarwal S, Deshpande SK, Sharma SK, Nair KGM. Changes in Structural and Optical Properties of Polycarbonate Induced by $\mathrm{Ag}^{+}$Ion Implantation. Journal of Macromolecular Science, Part B. 2010;49(2):259-268.

31. Weber RP, Suarez JCM. Behavior of polycarbonate armor: influence of gamma irradiation. Journal de Physique IV. 2006;134:941-947.
32. Oliveira LM, Araujo PLB, Araujo ES. The effect of gamma radiation on mechanical properties of biodegradable polymers poly(3-hydroxybutyrate) and poly (3-hydroxybutyrate-co-3hydroxyvalerate). Materials Research. 2013;16(1):195-203.

33. Chen $\mathrm{H}, \mathrm{Wu}$ J. Understanding the Underlying of the Essential Work of Fracture on the Molecular Level. Macromolecules. 2007;40(12):4322-4326.

34. Hossain MM, Lee CF, Fiscus DM, Sue HJ. Physical assessment of essential work of fracture parameters based on m-LLDPE blown films. Polymer. 2016;96:104-111. 